\title{
TRABALHO, PRAZER E SOFRIMENTO NA HOTELARIA
}

WORK, PLEASURE AND SUFFERING IN HOTELS

Recebido em 05.09.2016. Aprovado em 10.11.2016

Avaliado pelo sistema double blind review

DOI: http://dx.doi.org/10.12712/rpca.v10i4.662

\section{Laís Karla da Silva Barreto}

laisbarreto@gmail.com

Universidade Potiguar, Natal/RN, BRASIL

\section{Nilda Maria de Clodoaldo Pinto Guerra Leone}

nildaleone@unp.br

Universidade Potiguar, Natal/RN, BRASIL

\section{Jussele Lourenço da Silva Santiago}

jussele@unp.br

Universidade Potiguar, Natal/RN, BRASIL

\section{Annamaria Barbosa do Nascimento Nóbrega}

amarianobrega@unp.br

Universidade Federal do Rio Grande do Norte (UFRN), Natal/RN, BRASIL

\section{Resumo}

Esta pesquisa avalia as condições e organização do trabalho que se relacionam com a dinâmica do prazersofrimento dos colaboradores de uma Unidade de Alimentação e Nutrição Hoteleira. Foram adotados métodos quantitativos de pesquisa com o suporte do Inventário de Trabalho e Riscos de Adoecimento no estudo descritivo; tendo como participantes 15 funcionários de uma unidade de alimentação hoteleira. Os resultados apontaram uma predominância em vivências de sofrimento relacionadas ao contexto do trabalho que foram avaliados pelos trabalhadores de forma crítica ou grave, estando esses resultados evidenciados nos construtos: organização do trabalho, condições de trabalho, relações socioprofissionais, custo afetivo, custo cognitivo, custo físico, liberdade de expressão e falta de reconhecimento. Em contrapartida e de forma contraditória foram avaliados de forma satisfatória os danos relacionados ao trabalho.

Palavras-chave: Alimentação. Nutrição. Trabalho. Saúde.

\begin{abstract}
This research aims to evaluate the conditions and organization of work that relate to the dynamics of pleasuresuffering employees of a Unit of Nutrition Hospitality. We adopted quantitative research methods using the Inventory of Work and Risk of illness, and this is a descriptive study, in which 15 employees of a unit power hospitality participated. The results showed a predominance in distress experiences related to the context of the work that the workers were evaluated in a critical or severe, with results shown in this constructs: work organization, working conditions, social and professional relationships, cost affective, cognitive cost, cost physical, freedom of expression and lack of recognition. In contrast and in conflict were assessed satisfactorily damages related to work.
\end{abstract}

Keywords: Food. Nutrition. Work. Health. 


\section{Introdução}

A crescente divisão do trabalho, a rigidez, o autoritarismo e a baixa remuneração são dificuldades concretas que podem levar o trabalhador a sofrer. No entanto, o prazer pelo trabalho lhe proporciona melhor qualidade de vida, correlacionado ao alcance de metas intrínsecas e à sua realização profissional. Quando essa vivência de prazer acontece, o sofrimento não se revela um impedimento à produtividade.

Contudo, o trabalho constitui uma ação humanizada no contexto social, influenciado por aspectos, que propiciam o alcance dos objetivos organizacionais em busca de melhor qualidade no próprio trabalho, na satisfação e realização do trabalhador, tendo como consequência maior produtividade e competitividade das organizações (MEDEIROS, 2011).

O que ocorre, atualmente, é que as empresas exigem profissionais competentes e competitivos, mas nem sempre fornecem suporte organizacional capaz de promover a e beneficiar a saúde do trabalhador. Estabelece-se, então, uma distância entre o que a organização espera e prescreve, e o que o profissional realiza. Tal divergência implica custo humano que envolve dimensões físicas, psíquicas e cognitivas (BARROS; MENDES, 2003).

Dentro da dinâmica das Unidades de Alimentação, no mercado atual, Abreu (2009) destaca que o mercado encontra-se cada vez mais competitivo, pois de um lado, têm-se clientes mais exigentes e sofisticados, e, de outro, concorrentes mais agressivos e preparados. A combinação desses fatores passou a conduzir a atual dinâmica organizacional voltada para o aperfeiçoamento contínuo dos produtos e serviços.

Nesse sentido, há que se destacar que, usualmente, o trabalho pode ser uma fonte de sofrimento e não trazer satisfações, alegrias e prazer. Diante disso, pode-se afirmar que a insatisfação e a desmotivação no trabalho são preocupações de estudiosos, por afetarem muitos trabalhadores, nos mais diferentes níveis hierárquicos ou status que possuem na organização.

Este sofrimento no trabalho surge quando o trabalhador sente temor em não satisfazer às exigências da organização, como: de horário, de ritmo, de formação, de informação, de aprendizagem, de nível de instrução e capacitação, de experiência e de rapidez de aquisição de conhecimentos teóricos e práticos. Em suma, o sofrimento surge quando o indivíduo teme não se adaptar à cultura ou à ideologia da empresa, às exigências do mercado e às relações com o cliente (DEJOURS, 2006).

A forma como o trabalho é realizado permite a percepção da atividade como significativa ou não, influenciando o sentido particular que ela assume para cada sujeito. É a partir da construção desse sentido específico que surgem as vivências de prazersofrimento (FERREIRA; MENDES, 2001).

O prazer-sofrimento inscreve-se numa relação subjetiva do trabalhador com seu trabalho, que implica intersubjetividade no momento em que esse sujeito passa a relacionar-se com outros, sendo os valores, como princípios que guiam a vida da organização, um dos elementos responsáveis pela socialização das normas e regras, que definem formas específicas do trabalhador vivenciar sua tarefa e compartilhar suas relações sociais, afetivas e profissionais no contexto organizacional.

Com base nesse contexto, o presente estudo foi pautado nas relações dinâmicas entre organização do trabalho e processos de subjetivação que se manifestam nas vivências de prazer-sofrimento nos trabalhadores de Unidades de Alimentação e Nutrição Hoteleira, buscando desenvolver um entendimento sobre as estratégias de ação usadas para mediar contradições da organização do trabalho, nas patologias sociais e na saúde.

Diante do exposto, constitui-se a problemática central: quais as condições e organização do trabalho se relacionam com a dinâmica do prazer-sofrimento no trabalho dos colaboradores de uma Unidade de Alimentação e Nutrição Hoteleira?

Dentro dessa perspectiva, com o crescimento e o consequente aumento de competitividade na hotelaria nacional, os recursos humanos envolvidos na prestação de serviço obtêm papel de destaque, já que podem ser, os responsáveis pela qualidade percebida pelos clientes, o que, atualmente, é um dos fatores primordiais para o sucesso e fidelização dos mesmos (HOPNER, 2008).

Entender as características que definem um ambiente de trabalho para aqueles que o realizam, torna-se fundamental, pois orienta decisões e intervenções dos responsáveis pelos processos de transformação e melhoria organizacional das empresas e serviços. Aqui ressaltamos as melhorias na unidade de alimentação e nutrição do hotel pesquisado, podendo servir como 
referencial para as demais UANs. Nesta perspectiva, este trabalho tem como objetivo avaliar as condições e organização do trabalho que se relacionam com a dinâmica do prazer-sofrimento dos colaboradores de uma Unidade de Alimentação e Nutrição Hoteleira.

Apresente pesquisa justifica sua importância ao identificar e avaliar a organização e condições de trabalho estabelecidas que levam ao sofrimento em colaboradores e, a partir de então, propor estratégias que possam minimizar este quadro como um diferencial de qualidade organizacional.

Do ponto de vista prático, a análise serve como indicador para unidades hoteleiras, no que diz respeito aos processos relacionados à gestão de pessoas, para que os mesmos possam ser otimizados, gerando aumento da produtividade e estabelecendo diferencial no mercado de alimentação coletiva. Ressalta-se, ainda, que este setor está cada vez mais competitivo, buscando a excelência na prestação de serviço para manter-se no mercado.

\section{Conceitos sobre trabalho, prazer e sofrimento}

A palavra trabalho, originária do latim tripoliare, significava instrumento de tortura e punição, assumindo, assim, a ideia de sofrimento. $\mathrm{Na}$ medida em que os homens se viram obrigados a trabalhar, observou-se a organização desta atividade acompanhada de uma supressão do desejo pela necessidade real de subsistir (SANTOS, 2008).

Este conceito sofreu e vem sofrendo diversas alterações compatíveis com o crescimento demográfico, avanços tecnológicos e industrialização do processo produtivo. A qualidade de vida e de trabalho sempre foi alvo de reivindicações por parte dos trabalhadores, e a luta pela sobrevivência representou a primeira expressão de preocupação com a saúde, traduzida pelo ganho do não morrer no desempenho das penosas condições do trabalho.

O trabalho tornou-se parte fundamental da subsistência dos seres humanos, estando subordinado à sociedade $\mathrm{e}$, principalmente, às suas constantes e desenfreadas mudanças. É uma atividade a qual o ser humano dedica a maior parte de sua vida e tem proporcionado, em paralelo, a construção de um grande número de histórias de produção de sofrimento e de doenças ao longo da existência humana (LIMA, 2004).
Ketchum e Trist (1992) acreditam que os problemas de desempenho organizacional dependem da organização do trabalho e, mais precisamente, do grau de correspondência entre as características das pessoas e as propriedades das atividades desempenhadas.

A organização do trabalho compreenderia a divisão do trabalho ou de tarefas (compreende o modo operatório prescrito para a execução das tarefas: o conteúdo da tarefa) e a divisão dos homens (abrange a estrutura hierárquica, de comando, controle e relação entre os membros das equipes de trabalho, as relações socioprofissionais) (MEIRELES, 2006).

O trabalho, do ponto de vista social, segundo Kanaane (2007), é um elemento chave na formação da coletividade humana, e as mudanças tecnológicas têm implicado nas condutas e reações dos grupos e dos indivíduos. Já do ponto de vista psicológico, o trabalho é um fator que ativa mecanismos psicológicos e provoca diferentes graus de motivação e satisfação no trabalhador. É a forma como ele percebe o ambiente organizacional como facilitador ou não dos seus objetivos e necessidades.

Há concepções que enfocam ou definem o trabalho como meio de subsistência, um dano necessário; constroem uma visão do trabalho como obrigação, esforço ("sweatingsystem"-sistema do suor) e até mesmo como castigo. Nessa concepção, o trabalho é realizado para atender às necessidades imediatas de consumo, ao aumento da produção e ao desenvolvimento social. Em contrapartida, há concepções que têm o trabalho como meio para dignificar o homem por sua capacidade de produção, como forma de se autorrealizar. Assim, nessa outra vertente o trabalho passa a ser visto como possibilidade do homem construir-se a si mesmo e marcar sua existência na edificação do mundo (MENDES, 2007).

No entanto, o trabalho nem sempre funciona como fonte de crescimento, reconhecimento eindependência profissional e, muitas vezes, ele gera insatisfação, irritação, exaustão e adoecimento (DEJOURS, 1992). Dejours, Dessors eDesriaux (1993) apontam que o trabalho pode gerar desgastes, mas que é também um fator essencial para o equilíbrio e desenvolvimento do ser humano, importando nesta relação não tanto qual trabalho seja realizado, mas quais as condições para a realização deste.

Contudo, pode-se destacar que o trabalho possui um forte potencial de motivação sobre o trabalhador, 
sobre a organização e demais esferas da vida. O fato do trabalhador gostar do que faz, transforma seu cotidiano em fonte de satisfação e prazer (TOLEDO; GUERRA, 2009).

Shutz (1974) definiu o prazer como o sentimento que provém da realização do nosso potencial. E essa realização traz ao indivíduo o sentimento de que pode defrontar-se com seu meio ambiente; o sentimento de autoconfiança, de ser uma pessoa importante, competente e amigável, que tem capacidade de lidar com as situações à medida que surgem, que tem capacidade de usar plenamente suas próprias capacidades e de ser livre para expressar seus sentimentos.

Há ainda que se destacar que usualmente o trabalho pode ser uma fonte de sofrimento e não trazer satisfações, alegrias, prazer. Assim, a maior fonte do prazer é a realização e emprego de todos os recursos; o fracasso no uso deles leva, consequentemente, a uma ausência de prazer. Prado (1998) conceitua prazer da seguinte forma: "[...] é aquela sensação que temos quando algo nos acontece, ou que fazemos acontecer, que concorda com o nosso ser naquele momento".

O prazer é consequência do pleno desenvolvimento do funcionamento pessoal, ele surge quando o indivíduo realiza seu potencial para o sentimento, para a liberdade, e para a expressão total de si mesmo, no intuito de poder realizar tudo aquilo que ele é capaz, e para que ele possa também estabelecer relações satisfatórias com os outros e com a sociedade. E por fim, pode-se destacar que o sofrimento e prazer são provenientes da dinâmica interna das situações e da organização do trabalho. Surgem das relações subjetivas e de poder, e das ações dos trabalhadores permitidas pela organização do trabalho (TOLEDO; GUERRA, 2009).

As vivências de prazer-sofrimento formam um único constructo composto por três dimensões: "valorização" e "reconhecimento", que definem o prazer; e "desgaste com o trabalho", que define o sofrimento. $O$ prazer é vivenciado quando são experimentados sentimentos de valorização e reconhecimento no trabalho. A valorização é o sentimento de que o trabalho tem sentido e valor por si mesmo, é importante e significativo para a organização e a sociedade. O reconhecimento é o sentimento de ser aceito e admirado no trabalho e ter liberdade para expressar sua individualidade. O sofrimento é vivenciado quando experimentado o desgaste em relação ao trabalho, que significa a sensação de cansaço, desânimo e descontentamento com o trabalho. Assim sendo, prazer-sofrimento são vivências de sentimentos de valorização, reconhecimento e/ou desgaste no trabalho (MENDES, 2001).

O sofrimento no trabalho surge quando o trabalhador sente temor em não satisfazer às exigências da organização do trabalho, como: de horário, de ritmo, de formação, de informação, de aprendizagem, de nível de instrução e capacitação, de experiência e de rapidez de aquisição de conhecimentos teóricos e práticos. Em suma, o sofrimento surge quando o trabalhador teme não se adaptar à cultura ou à ideologia da empresa, às exigências do mercado e às relações com o cliente (DEJOURS, 2006).

Dejours, Abdoucheli e Jayet (1994) faz a distinção entre o sofrimento patogênico e o sofrimento criador. O primeiro encaminharia o indivíduo para incidentes e acidentes no trabalho, para a fadiga psicossomática. Poderia ilustrar, também, como consequência do sofrimento, os casos específicos de doenças ocupacionais, como, por exemplo, o estresse no trabalho. Ainda, quando as normas são extremamente rígidas e não há liberdade para que o indivíduo intervenha na organização do trabalho, poderá causar uma alienação do desejo e o trabalho passará a não ter mais sentido e valor.

Já quando o sofrimento pode ser transformado em criatividade, ele beneficia o sujeito, aumentando sua resistência ao risco de desestabilização psíquica e somática. Isto é, o sofrimento criador propicia ao indivíduo uma condição de reverter a situação geradora de sofrimento, transformando-a em uma situação prazerosa, uma vez que ele obterá ganhos, apesar do sofrimento vivenciado.

Considerando-se a complexidade nos conceitos de prazer e sofrimento, assim como a relação do indivíduo com o trabalho, ou seja, compreendendo as contradições das condições e organização do trabalho que se manifestam nas vivências de prazer-sofrimento, torna-se imprescindível conhecer o ambiente que provavelmente seja alvo desse constructo.

\section{Unidades de alimentação e nutrição hoteleira}

Segundo Abreu etal. (2009), uma Unidade de Alimentação e Nutrição (UAN) pode ser definida 
como um serviço organizado que desenvolve uma sequência e sucessão de atos destinados a fornecer refeições balanceadas dentro dos padrões dietéticos e higiênicos, visando, assim, atender às necessidades nutricionais de seus clientes.

O objetivo de uma Unidade de Alimentação e Nutrição é o fornecimento de uma refeição equilibrada nutricionalmente, apresentando bom nível de sanidade, e que seja adequada ao comensal, denominação dada ao consumidor em alimentação coletiva (PROENÇA, 2009).

Do mesmo modo, Ribeiro (2002) ressalta que as UANs são áreas de produção de refeições, ou seja, estabelecimentos que trabalham como única finalidade de comprar, receber e armazenar alimentos in natura ou semiprocessados e processá-los, para posterior distribuição de refeições a diferentes tipos de clientelas, buscando alimentar de forma correta a população de forma quantitativa e qualidade microbiológica e de nutrição, ofertando nutrientes essenciais para a sobrevivência e manutenção do indivíduo.

Em resumo, a UAN é um conjunto de áreas com o objetivo de operacionalizar o provimento nutricional de coletividades. (ABREU, 2009) e dentro destes estabelecimentos, todos os processos administrativos, operacionais e de controle devem ocorrer, tal como uma unidade fabril ou indústria clássica (RIBEIRO, 2002).

As UANs se caracterizam por alimentar as pessoas fora de seu domicílio, e atuam em diversos locais do país: no trabalho, na escola, nos hospitais, em serviços de bordo, em restaurantes comerciais e em refeitórios das forças armadas (ALVES, 2005).

Este setor pode ser dividido em alimentação comercial e alimentação coletiva, sendo que os estabelecimentos que trabalham com produção e distribuição de alimentação para coletividades, é que atualmente recebem o nome de Unidade de Alimentação e Nutrição (PROENÇA, 2009).

No Brasil, o setor hoteleiro, historicamente, foi constituído por empresas familiares. A partir da década de 1970, algumas cadeias internacionais passaram a se instalar no Brasil trazendo um novo conceito de qualidade em serviços hoteleiros, com altos padrões, tanto de instalações físicas quanto de formação dos seus recursos humanos. Em decorrência da entrada dessas cadeias ou redes de hotéis, sobretudo na década de 1990, ocorreu uma verdadeira transformação no setor, com muitas empresas pequenas e familiares encerrando suas atividades ou sendo forçadas a mudarem a sua estratégia para permanecerem competitivas no mercado (HOPNER, 2008).

Os restaurantes hoteleiros (ou de hospedagem) são aqueles presentes dentro de hotéis, sendo seu objetivo principal o atendimento e satisfação do hóspede ou similar, podendo ser de preços econômicos, moderados e altos (FONSECA, 2006). Tais estabelecimentos apresentam características complexas de produção, durante turnos contínuos necessitando de mãode-obra especializada e matéria prima de excelente qualidade, além de uma estrutura física que permita a conservação dos alimentos e execução das atividades em ambientes sadios.

Alves (2005) destaca que as atividades do Setor de Alimentação Coletiva têm evoluído consideravelmente e que atualmente apresenta grande crescimento e uma competitividade expressiva. É importante destacar que, assim como os demais setores da economia, ele vem se transformando a fim de evoluir, atender novas exigências de seus clientes e garantir maior espaço no mercado.

As Unidades de Alimentação e Nutrição, de acordo com Teixeira (2004), são órgãos de estrutura administrativa simples, porém de funcionamento complexo, visto que, em geral, neles são desenvolvidas atividades que se enquadram nas funções técnicas, administrativas, comerciais, financeira, contábil e de segurança, funções estas imprescindíveis a qualquer empresa, independente de seu tamanho ou personalidade jurídica.

\section{Trabalho, prazer e sofrimento em uan}

No setor em estudo, várias pesquisas sobre as Unidades de Alimentação e Nutrição (UAN) revelam as condições complexas de organização e condições de trabalho, envolvendo: ritmos intensos, horários prolongados, altos índices de rotatividade e de absenteísmo, elevados índices de ruídos, temperaturas elevadas, pouca iluminação e espaço físico mal dimensionado (COLARES; FREITAS, 2007).

Apesar do desenvolvimento tecnológico, no que diz respeito à matéria prima, equipamentos e métodos de trabalho, o processo produtivo em UAN adota até hoje o modelo taylorista/fordista, visto que as plantas físicas das cozinhas são projetadas segundo o princípio 
da 'marcha avante', que simula o movimento de uma esteira (LANZILLOT'TI, 1996).

A variedade de tarefas, a concomitância de atividades, o imediatismo de processos e de produtos, a larga lista de insumos utilizados em cada atividade, aliado à heterogeneidade de hábitos, a falta de comprometimento, conhecimento, treinamento $\mathrm{e}$ adequação de colaboradores, acaba tornando o diaa-dia das UANs um complexo contexto de estudo e gerenciamento (RIBEIRO, 2002).

A preocupação sobre as condições de trabalho na saúde dos trabalhadores é abordada por diferentes modelos, conceitos e práticas. Já que é no trabalho que passamos a maior parte de nossa vida, os reflexos das condições de trabalho irão refletir sobre o nosso bem estar mesmo fora da jornada de trabalho (COLARES, 2005).

Nessa perspectiva, a preocupação com a saúde do operador de UAN começa a surgir no setor de alimentação coletiva, na medida da conscientização de que condições de trabalho e saúde estão diretamente relacionados com performance e produtividade (MATOS, 2000).

Assim, a gestão do restaurante deve ser conduzida com objetivos bem definidos, pois surgem muitos imprevistos e detalhes que interferem na sua configuração. A definição clara do que se pretende, segurança quanto à forma de conduzir os processos e objetividade são pontos que precisam apresentar respostas claras e consolidação para todas as fases do trabalho (LOBO, 2009).

A configuração da situação de trabalho como prazerosa ou não está relacionada ao modo como o trabalhador lida com tal situação. As variáveis 'prazer' e 'sofrimento' são resultantes da relação do indivíduo com a organização, consigo mesmo, com outros indivíduos e com o meio no qual está inserido. Podese dizer, ainda, que cada relação é determinada pela história passada dos sujeitos e pela tensão dialética entre os sentimentos de prazer e sofrimento nas situações de trabalho. Assim, o que para uns pode ser sentido como prazeroso não o será necessariamente para outros (TORRES; ABRAHÃO, 2006).

Desse modo, a organização de trabalho é a principal fonte de desestabilização da saúde mental dos trabalhadores (DEJOURS, 1988). A saúde psíquica decorre da dinâmica da busca de prazer e evitação do sofrimento. Por outro lado, o sofrimento não é patológico, mas é um sinal de alerta para evitar o adoecimento.

A organização de trabalho está atrelada a diversos fatores, como por exemplo, à repetitividade, à monotonia, à incapacidade de uma visão do todo do processo de trabalho, à adoção de técnicas disciplinares, ao controle do tempo de execução e dos movimentos físicos dos trabalhadores, à transferência da dimensão intelectual do trabalho para esferas gerenciais e às estruturas hierarquizadas. Enfim, todas essas características fazem parte dos pressupostos do Taylorismo, que conduzem a um sistema de trabalho nefasto, em que o trabalhador termina por ignorar o sentido do seu trabalho e o destino da sua tarefa (PEREIRA, 2003; RESENDE, 2003).

Dessa forma, a realidade dos contextos nos quais o trabalho é produzido necessita de transformações em termos de organização, condições e relações sociais que, sem a gestão dessas dimensões do trabalho, tornase muito difícil o espaço público de fala e cooperação. Sendo assim, a construção dessas oportunidades transforma-se em um desafio (COLARES, 2005). É importante que ações sejam desenvolvidas, de modo a impedir o adoecimento dos trabalhadores em decorrência da impossibilidade de o trabalho assumir um sentido de prazer

\section{Metodologia}

Trata-se de uma pesquisa descritiva, tendo em vista que expõe características de uma população ou fenômeno e estabelece correlações entre variáveis. Classifica-se como estudo de caso de natureza quantitativa, por abranger em ambiente empresarial, os fatos de uma determinada realidade e apresentar informações por meio de estatística descritiva (VERGARA, 2006; YIN, 2001). O presente estudo foi realizado em um setor da empresa denominado de Unidade de Alimentação e Nutrição (UNA) de um Hotel com padrão quatro estrelas, situado na via costeira do município de Natal/ $\mathrm{RN}$, onde se concentra a maior estrutura de rede hoteleira do estado. O Hotel foi fundado em 1991 por um grupo familiar, sendo até hoje caracterizado como uma empresa familiar.

Os participantes da pesquisa totalizaram 15 colaboradores da UNA vinculados à gerência de alimentos e bebidas do hotel e caracterizou-se como pesquisa censitária. Este setor pode ser considerado como um serviço de autogestão, sendo a empresa 
responsável por todo o processo, envolvendo instalação, equipamentos, contratação de pessoal e gerenciamento do processo produtivo das refeições. Estas perfazem uma média diária de 915 refeições, na alta estação, relativo a funcionários e hóspedes; e, na baixa estação, 240 .

No Quadro 1 encontram-se as variáveis estudadas na pesquisa, através do Inventário sobre o Trabalho e Riscos de Adoecimento (ITRA), contendo as quatro escalas com as suas respectivas dimensões.

Quadro 1. Inventário sobre o Trabalho e Riscos de Adoecimento (ITRA)

\begin{tabular}{|c|c|c|}
\hline & ESCALAS & DIMENSÕES \\
\hline \multirow{13}{*}{ 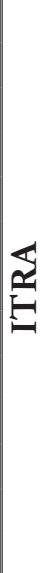 } & \multirow{3}{*}{$\begin{array}{l}\text { Contexto do } \\
\text { trabalho }\end{array}$} & Organização do trabalho \\
\hline & & Relações socioprofissionais \\
\hline & & Condições de trabalho \\
\hline & \multirow{3}{*}{$\begin{array}{c}\text { Custo Humano } \\
\text { no Trabalho }\end{array}$} & Custo Afetivo \\
\hline & & Custo Cognitivo \\
\hline & & Custo Físico \\
\hline & \multirow{4}{*}{$\begin{array}{c}\text { Prazer e } \\
\text { Sofrimento }\end{array}$} & Liberdade de Expressão \\
\hline & & Realização Profissional \\
\hline & & Esgotamento Profissional \\
\hline & & Falta de Reconhecimento \\
\hline & \multirow{3}{*}{$\begin{array}{c}\text { Danos } \\
\text { Relacionados ao } \\
\text { Trabalho }\end{array}$} & Danos Físicos \\
\hline & & Danos Sociais \\
\hline & & Danos Psicológicos \\
\hline
\end{tabular}

Fonte: Adaptado de Mendes, (2007)

A empresa informou aos funcionários sobre a pesquisa e, de acordo com a disponibilidade dos mesmos, por meio de conversa individualizada com os 15 funcionários, explicou-se os objetivos do estudo e solicitou-se a colaboração dos mesmos. Foi entregue a carta de autorização aos entrevistados para que os mesmos tomassem conhecimento e as assinasse, garantindo anonimato e informando que suas respostas não produziriam nenhum prejuízo pessoal ou para seu emprego. Apesar de o questionário ser autoaplicável, o mesmo foi lido em voz alta, objetivando esclarecer possíveis dúvidas.

Em seguida, foi realizada a pesquisa por meio da aplicação de questionários, elaborados em quatro partes denominado Inventário sobre o Trabalho e Riscos de Adoecimento (ITRA), que constitui instrumento estruturado que tem por objetivo traçar um perfil dos antecedentes, medidores e efeitos do trabalho no processo de adoecimento. Tal instrumento tem como objetivo atender à necessidade gerada pelo aumento das pesquisas em psicodinâmica do trabalho em grandes grupos de trabalhadores (MENDES, 2007).

O ITRA foi criado e validado, inicialmente, por Ferreira e Mendes (2003), tendo sofrido adaptações e revalidações no ano de 2004, 2005 e, por último, em 2006 (MENDES, 2007), sendo esta última validação a utilizada neste estudo.

Com o objetivo de mensurar distintas e interdependentes modalidades de representações dos respondentes, o Inventário sobre o Trabalho e Riscos de Adoecimento (ITRA) está estruturado em quatro escalas interdependentes para avaliar quatro dimensões da inter-relação trabalho e riscos de adoecimento, e para a avaliação de cada uma dessas escalas foi utilizado uma escala de frequência tipo Likert abaixo discriminada:

a) o contexto do trabalho: são representações relativas à organização, às relações socioprofissionais e às condições de trabalho. Esses dados são avaliados pela Escala de Avaliação do Contexto de Trabalho (EACT). Escala de frequência Likert de 1 a 5.

b) as exigências: são representações relativas ao custo físico, cognitivo e afetivo do trabalho que são avaliados pela Escala de Custo Humano no Trabalho (ECHT). Escala de frequência Likert de 1 a 5 .

c) o sentido do trabalho: são representações relativas às vivências de prazer e de sofrimento no trabalho. Estes são avaliados pela Escala de Indicadores de Prazer e Sofrimento no Trabalho (EIPST). Escala de frequência Likert de 0 a 6.

d) os efeitos do trabalho para a saúde: são representações relativas às consequências em termos de danos físicos e psicossociais. Essas são avaliadas pela Escala de Avaliação dos Danos Relacionados ao Trabalho (EADRT). Escala de frequência Likert de 0 a 5.

O processamento dos dados obedeceu à seguinte sequência: codificação, tabulação, organização e tratamento estatístico. Para caracterização dos pesquisados, através das variáveis sociodemográficas, foi utilizada a estatística descritiva, através das frequências simples, absolutas e médias dos dados gerados com a pesquisa realizada.

Os dados referentes ao Inventário sobre o Trabalho e Riscos de Adoecimento (ITRA) foram tratados no 
Excel, através do qual foram realizadas estatísticas descritivas, tais como frequência, média e desvio padrão, e calculado o Coeficiente Alpha de Cronbach, com vistas ao estabelecimento da consistência interna.

\section{Resultados da pesquisa}

No que se refere ao perfil sociodemográfico dos entrevistados, $86,67 \%$ encontram-se na faixa de 20 a 30 anos; $80 \%$ são do gênero masculino. Com ensino médio são $80 \%$; com estado civil de solteiros são $60 \%$; com tempo de serviço de até dois anos são $73,33 \%$ na unidade, e tempo no cargo, 66,67\%. Têm exame médico $53,33 \%$ e os que não tiveram nenhum tipo de afastamento são $46,67 \%$.

O Contexto de Trabalho dos funcionários da Unidade de Alimentação Hoteleira foi investigado a partir das três dimensões - Organização do Trabalho, Condições de Trabalho e Relações Socioprofissionais. No Quadro 2, a seguir, apresentam-se essas dimensões com o resumo dos itens avaliados com maiores médias.

Quadro 2 . Resumo sobre EACT: dimensões e itens avaliados com maiores médias

\begin{tabular}{|c|c|c|}
\hline \multirow{3}{*}{$\begin{array}{l}\text { Contexto } \\
\text { do trabalho }\end{array}$} & $\begin{array}{l}\text { Organização do } \\
\text { trabalho }\end{array}$ & $\begin{array}{l}\text { - O ritmo de trabalho } \\
\text { é excessivo } \\
- \text { As tarefas são } \\
\text { repetitivas } \\
\text { - Falta tempo para } \\
\text { realizar pausas de } \\
\text { descanso no trabalho }\end{array}$ \\
\hline & $\begin{array}{c}\text { Relações } \\
\text { socioprofissionais }\end{array}$ & $\begin{array}{l}\text { - Os funcionários são } \\
\text { excluídos das decisões } \\
-\quad \text { A comunicação } \\
\text { entre funcionários é } \\
\text { insatisfatória } \\
\text { - Falta apoio das o } \\
\text { meu desenvolvimento } \\
\text { profissional }\end{array}$ \\
\hline & $\begin{array}{c}\text { Condições de } \\
\text { trabalho }\end{array}$ & $\begin{array}{l}\text { - O ambiente físico é } \\
\text { desconfortável } \\
\text { - Existe muito } \\
\text { barulho no ambiente } \\
\text { de trabalho } \\
\text { - Os instrumentos } \\
\text { de trabalho são } \\
\text { insuficientes para } \\
\text { realizar as tarefas }\end{array}$ \\
\hline
\end{tabular}

Fonte: Dados da Pesquisa, 2012.
A primeira dimensão da EACT, Organização do Trabalho, é definida como a divisão e conteúdo das tarefas, normas, controles e ritmos de trabalho, referente às concepções e modos de gestão de pessoas e do trabalho que permeiam o contexto de trabalho. De acordo com o que se observa no Quadro 2, para essa dimensão, os itens que obtiveram as maiores médias foram "o ritmo de trabalho é excessivo"; "as tarefas são repetitivas" e "falta tempo para realizar pausas de descanso no trabalho", todos $\operatorname{com} \mu=4,00$. Cabe ressaltar que os valores obtidos do Alpha Cronbach demonstraram uma boa consistência interna da escala (Tabela 1).

Observa-se, através dos resultados apresentados na Tabela 1, que a maioria dos respondentes avaliou a unidade entre os níveis grave e crítico, tendo em vista que $46,67 \%$ avaliaram como grave, e outros $46,67 \%$ dos funcionários como crítico, indicando que existe uma percepção negativa dessa dimensão na Unidade.

Tabela 1. Percentual dos níveis e das dimensões da EACT

\begin{tabular}{l|c|c|c}
\hline Níveis & $\begin{array}{c}\text { Organização } \\
\text { do trabalho }\end{array}$ & $\begin{array}{c}\text { Relações } \\
\text { sociopro- } \\
\text { fissionais }\end{array}$ & $\begin{array}{c}\text { Condições de } \\
\text { trabalho }\end{array}$ \\
\hline Grave & $\mathbf{4 6 , 6 7 \%}$ & $6,67 \%$ & $13,33 \%$ \\
\hline Crítico & $\mathbf{4 6 , 6 7 \%}$ & $\mathbf{6 6 , 6 7 \%}$ & $\mathbf{6 0 , 0 0 \%}$ \\
\hline Satisfatório & $6,67 \%$ & $26,67 \%$ & $26,67 \%$ \\
\hline
\end{tabular}

Fonte: Dados da Pesquisa, 2012.

Os resultados das médias gerais desta dimensão $(\mu=$ $3,43 ; \sigma=0,56)$ indicam que a dimensão Organização do Trabalho apresentou avaliações críticas quanto à saúde dos profissionais, conforme pode ser observado na Tabela 2.

Tabela 2 . Estatística descritiva referente às dimensões da EACT.

\begin{tabular}{l|c|c|c}
\hline \multicolumn{1}{c|}{ Dimensões } & Média & $\begin{array}{c}\text { Desvio } \\
\text { Padrão }\end{array}$ & $\begin{array}{c}\text { Alpha } \\
\text { Cronbach }\end{array}$ \\
\hline $\begin{array}{l}\text { Organização do } \\
\text { trabalho }\end{array}$ & 3,43 & 0,56 & 0,68 \\
\hline $\begin{array}{l}\text { Relações } \\
\text { socioprofissionais }\end{array}$ & 2,57 & 0,76 & 0,78 \\
\hline $\begin{array}{l}\text { Condições de } \\
\text { trabalho }\end{array}$ & 2,77 & 0,80 & 0,80 \\
\hline
\end{tabular}

Fonte: Dados da Pesquisa, 2012. 
No que diz respeito às Relações Socioprofissionais, a segunda dimensão da EACT, definida como gestão do trabalho, comunicação e interação profissional, observou-se que a maioria $(66,67 \%)$ avaliou como crítico o risco de adoecer para esta dimensão (Tabela 1). Os resultados das médias gerais $(\mu=2,57 ; \sigma=0,76)$, segundo Tabela 2 , mostram que a dimensão relações socioprofissionais apresentou avaliações críticas quanto à saúde dos profissionais.

Nesta dimensão, os itens que obtiveram as maiores médias,segundo Quadro 2, foram "os funcionários são excluídos das decisões"; "a comunicação entre funcionários é insatisfatória"; "falta apoio das chefias para o meu desenvolvimento profissional" com médias $\mu=3,27, \mu=2,73$ e $\mu=$ 2,73 , respectivamente.

Existe um discurso das instituições, no geral, de promover um maior envolvimento dos trabalhadores na gestão do trabalho, no entanto, se mantém a premissa básica do modelo taylorista-fordista, em que se separa o planejamento da execução do trabalho. Marcam-se, então, nitidamente as dimensões do trabalho prescrito (tarefa) e o trabalho real (atividade) (BARROS; MENDES, 2003).

A organização do trabalho nos moldes tayloristafordista instiga os trabalhadores para uma disputa profissional por se confrontarem individualmente com as cobranças de produtividade (DEJOURS, 1992).

Por fim, foi avaliada a dimensão Condições de Trabalho da EACT, que é definida como a qualidade do ambiente físico, do posto de trabalho, dos equipamentos e do material disponibilizado para execução do trabalho. Esta, como as demais dimensões, foi avaliada de forma crítica por $60 \%$ dos funcionários (Tabela 1). Os resultados das médias gerais $(\mu=2,77$; $\sigma=0,80)$, conforme Tabela 2 , mostram que esta dimensão apresentou avaliações críticas quanto à saúde dos profissionais. Nesta dimensão, os itens que obtiveram as maiores médias foram, conforme Quadro 2,“o ambiente físico é desconfortável”; "existe muito barulho no ambiente de trabalho"; “os instrumentos de trabalho são insuficientes para realizar as tarefas" com médias $\mu=3,20, \mu=$ 3,67 e $\mu=3,60$, respectivamente.

Pode-se verificar que o Contexto de Trabalho Organização do Trabalho, Condições de Trabalho e Relações Socioprofissionais, foi avaliado de forma crítica entre os funcionários da unidade de alimentação hoteleira. Contudo, faz-se necessário avaliar as demais dimensões do Inventário sobre o Trabalho e Riscos de Adoecimento (ITRA) que revela a inter-relação trabalho e riscos de adoecimento, o que é realizado adiante.

A Escala do Custo Humano do Trabalho (EACHT) é mensurada por meio de três dimensões: física, cognitiva e afetiva, e expressa o que deve ser despendido pelos trabalhadores (individual e coletivamente) nas esferas física, cognitiva e afetiva, a fim de responderem às exigências de tarefas (formais e/ou informais) postas num contexto de produção. No Quadro 3, a seguir, apresentam-se essas dimensões com o resumo dos itens avaliados com maiores médias.

Quadro 3 . Resumo sobre ECHT, suas dimensões e itens avaliados com maior média

\begin{tabular}{|c|c|c|}
\hline \multirow{3}{*}{$\begin{array}{c}\text { Custo } \\
\text { Humano } \\
\text { no } \\
\text { Trabalho }\end{array}$} & $\begin{array}{l}\text { Custo } \\
\text { Afetivo }\end{array}$ & $\begin{array}{l}\text { - Ter que lidar com ordens } \\
\text { contraditórias } \\
\text { - Ser obrigado a cuidar da } \\
\text { aparência física } \\
\text { - Transgredir valores } \\
\text { éticos }\end{array}$ \\
\hline & $\begin{array}{c}\text { Custo } \\
\text { Cognitivo }\end{array}$ & $\begin{array}{l}\text { - Ter que resolver } \\
\text { problemas } \\
\text { - Ser obrigado a lidar com } \\
\text { imprevistos } \\
\text { - Usar a visão de forma } \\
\text { contínua }\end{array}$ \\
\hline & $\begin{array}{l}\text { Custo } \\
\text { Físico }\end{array}$ & $\begin{array}{l}\text { - Usar braços de forma } \\
\text { contínua } \\
\text { - Caminhar } \\
\text { - Ser obrigado a ficar em } \\
\text { pé } \\
\text { - Usar as mãos de forma } \\
\text { repetida }\end{array}$ \\
\hline
\end{tabular}

Fonte: Dados da Pesquisa, 2012.

$\mathrm{Na}$ primeira dimensão da ECHT, Custo Afetivo, definida como dispêndio emocional, sob a forma de reações afetivas, sentimentos e estados de humor, conforme Quadro 3, os itens que obtiveram as maiores médias foram "ter que lidar com ordens contraditórias"; "ser obrigado a cuidar da aparênciafísica"; "transgredirvalores éticos", com médias $\mu=3,47, \mu=3,07$ e $\mu=3,07$, respectivamente. 
Na segunda dimensão, Custo Cognitivo, relacionada ao dispêndio intelectual para aprendizagem, resolução de problemas e tomada de decisão no trabalho, os itens que obtiveram as maiores médias foram "ter que resolver problemas"; "ser obrigado a lidar com imprevistos"; "usar a visão de forma contínua", com médias $\mu=3,40, \mu=3,73$ e $\mu=3,33$, respectivamente, de acordo com o Quadro 3.

Finalizando a ECHT, na avaliação do Custo Físico, que diz respeito ao esforço corporal imposto aos trabalhadores em função das características do contexto de trabalho, os itens que obtiveram as maiores médias foram "usar braços de forma contínua"; "caminhar"; "ser obrigado a ficar em pé"; "usar as mãos de forma repetida" com médias $\mu=3,80, \mu=4,00, \mu=3,80$ e $\mu=4,47$, respectivamente. $\mathrm{Na}$ Tabela 3, a seguir, é apresentado o percentual dos respondentes para as três dimensões do EACHT, de acordo com os seus respectivos níveis.

Tabela 3 . Percentual dos respondentes para a EACHT

\begin{tabular}{l|c|c|c}
\hline \multicolumn{1}{c|}{ Níveis } & $\begin{array}{c}\text { Custo } \\
\text { Afetivo }\end{array}$ & $\begin{array}{c}\text { Custo } \\
\text { Cognitivo }\end{array}$ & $\begin{array}{c}\text { Custo } \\
\text { Físico }\end{array}$ \\
\hline Grave & $0 \%$ & $15 \%$ & $\mathbf{6 0 \%}$ \\
\hline Crítico & $\mathbf{6 0 \%}$ & $40 \%$ & $20 \%$ \\
\hline Satisfatório & $40 \%$ & $33,33 \%$ & $20 \%$ \\
\hline
\end{tabular}

Fonte: Dados da Pesquisa, 2012.

Com base na Tabela 3, observa-se que a dimensão Custo Afetivo foi avaliado por $60 \%$ dos funcionários como crítico, embora os demais pesquisados $(40 \%)$ tenham avaliado como satisfatório. A dimensão Custo Cognitivo foi avaliada também como crítico, por $40 \%$ dos funcionários. Para a dimensão Custo Físico, a maioria dos respondentes (60\%) avaliou como grave o risco de adoecer. $\mathrm{Na}$ Tabela 4, a seguir, são apresentados os resultados das médias gerais das três dimensões do EACHT.

Tabela 4 . Estatística descritiva referente às dimensões da ECHT

\begin{tabular}{l|c|c|c}
\hline \multicolumn{1}{c|}{ Dimensões } & Média & $\begin{array}{c}\text { Desvio } \\
\text { Padrão }\end{array}$ & $\begin{array}{c}\text { Alpha } \\
\text { Cronbach }\end{array}$ \\
\hline Custo Afetivo & 2,55 & 0,76 & 0,73 \\
\hline Custo Cognitivo & 3,01 & 0,98 & 0,86 \\
\hline
\end{tabular}

\begin{tabular}{l|c|c|c}
\hline Custo Físico & 3,45 & 1,01 & 0,87 \\
\hline
\end{tabular}

Fonte: Dados da Pesquisa, 2012.

De acordo com a Tabela 4, os resultados das médias gerais $(\mu=2,55 ; \sigma=0,76)$ mostram que a dimensão Relações Custo Afetivo apresentaram avaliações críticas quanto à saúde dos profissionais. Para a dimensão Custo Cognitivo, os resultados das médias gerais $(\mu=3,01 ; \sigma=0,98)$ mostram que a dimensão Relações Custo Cognitivo apresentaram avaliações críticas quanto à saúde dos profissionais. Os resultados das médias gerais $(\mu=3,45 ; \sigma=1,01)$, para a dimensão Custo Físico, também mostram que esta dimensão apresentou avaliações críticas quanto à saúde dos profissionais.

As exigências do trabalho mostram que os riscos para saúde dos trabalhadores revelam-se como uma possibilidade para o desenvolvimento de doenças ocupacionais, quer seja pela elevada carga física de trabalho, a que são submetidos diariamente os colaboradores, pela exigência de movimentos repetitivos na execução das tarefas, pela pressão temporal do trabalho, pelo estresse advindo da possibilidade do risco da perda de emprego, uma vez que na baixa estação reduz o quadro. Soma-se a esta situação a exposição dos trabalhadores a um elevado nível de ruído e ao desconforto térmico encontrado no ambiente de trabalho.

Passa-se, agora, à discussão das dimensões e itens da EIPST (Escala de Indicadores de Prazer e Sofrimento no Trabalho), que é avaliada através de quatro dimensões: duas avaliam o prazer - realização profissional e liberdade de expressão - e duas avaliam o sofrimento no trabalho - falta de reconhecimento e esgotamento profissional, conforme apresentado no Quadro 4. 
Quadro 4 . Resumo sobre EIPST, suas dimensões e itens avaliados com maiores médias

\begin{tabular}{|c|c|c|}
\hline \multirow{4}{*}{ Prazer e Sofrimento } & Liberdade de Expressão & $\begin{array}{ll}\text { - } & \text { Solidariedade entre os colegas } \\
\text { - } & \text { Cooperação entre os colegas } \\
\text { - } & \text { Satisfação }\end{array}$ \\
\hline & Realização Profissional & $\begin{array}{ll}- & \text { Motivação } \\
\text { - } & \text { Orgulho pelo que faço } \\
- & \text { Bem-estar } \\
\end{array}$ \\
\hline & Esgotamento Profissional & $\begin{array}{ll}- & \text { Esgotamento emocional } \\
\text { - } & \text { Estresse } \\
\text { - } & \text { Sobrecarga } \\
\end{array}$ \\
\hline & Falta de Reconhecimento & $\begin{array}{ll}\text { - } & \text { Falta de reconhecimento de meu esforço } \\
\text { - } & \text { Falta de reconhecimento de meu desempenho } \\
\text { - } & \text { Injustiça }\end{array}$ \\
\hline
\end{tabular}

Fonte: Dados da Pesquisa, 2012.

Para as dimensões do Prazer, considerando-se que os itens são positivos, a primeira dimensão avaliada foi liberdade de expressão, definida como a vivência de gratificação profissional, orgulho e identificação com o trabalho que faz. Os itens desta dimensão que obtiveram as maiores médias foram "solidariedade entre os colegas"; "cooperação entre os colegas"; "satisfação" com médias $\mu=3,67 \mu=3,40$, e $\mu=3,80$, respectivamente, conforme Quadro 4. Observa-se, ainda, através dos resultados apresentados na Tabela 5, que a maioria (80\%) dos respondentes avaliou a UAN como crítico, mostrando que existe uma percepção negativa dessa dimensão.

Tabela 5 .Percentual dos respondentes para a Escala do Prazer e Sofrimento do Trabalho

\begin{tabular}{l|c|c|c|c}
\hline \multicolumn{1}{c|}{ Níveis } & $\begin{array}{c}\text { Liberdade de } \\
\text { Expressão }\end{array}$ & $\begin{array}{c}\text { Realização } \\
\text { Profissional }\end{array}$ & $\begin{array}{c}\text { Esgotamento } \\
\text { Profissional }\end{array}$ & $\begin{array}{c}\text { Falta de } \\
\text { Reconhecimento }\end{array}$ \\
\hline Grave & $13,33 \%$ & $33,33 \%$ & $33,33 \%$ & $6,67 \%$ \\
\hline Crítico & $\mathbf{8 0 \%}$ & $33,33 \%$ & $33,33 \%$ & $\mathbf{5 3 , 3 3 \%}$ \\
\hline Satisfatório & $6,67 \%$ & $33,33 \%$ & $33,33 \%$ & $40 \%$ \\
\hline
\end{tabular}

Fonte: Dados da Pesquisa, 2012.

$\mathrm{Na}$ Tabela 6, pode ser vista a estatística descritiva sobre as dimensões dessa escala. Os resultados das médias gerais $(\mu=2,58 ; \sigma=0,88)$ mostram que a dimensão liberdade de expressão apresentou avaliações críticas para vivências de prazer no trabalho.

Tabela 6 . Estatística descritiva referente às dimensões da EIPST

\begin{tabular}{l|c|c|c}
\hline \multicolumn{1}{c|}{ Dimensões } & Média & Desvio Padrão & Alpha Cronbach \\
\hline Liberdade de Expressão & 2,58 & 0,88 & 0,45 \\
\hline Realização Profissional & 2,70 & 1,47 & 0,83 \\
\hline Esgotamento Profissional & 3,01 & 1,63 & 0,85 \\
\hline Falta de Reconhecimento & 2,37 & 1,43 & 0,82 \\
\hline
\end{tabular}

Fonte: Dados da Pesquisa, 2012. 
Ainda segundo dados da Tabela 6, os resultados das médias gerais $(\mu=2,70 ; \sigma=1,47)$ mostram que a dimensão Realização Profissional apresentou avaliações críticas quanto à vivência de prazer. Nesta dimensão, os itens que obtiveram as maiores médias foram "motivação"; "orgulho pelo que faço"; "bem-estar" com médias $\mu=3,13, \mu=4,27$, e $\mu=3,13$, respectivamente. No entanto, o único item considerado satisfatório pelos funcionários foi o "orgulho pelo que faço", contribuindo para a avaliação positiva dessa dimensão. Contudo, os outros itens não foram bem avaliados, tornando a avaliação dessa dimensão moderada.

Esta avaliação crítica torna-se preocupante para a organização, considerando-se o que assevera Dejours (2004), ao afirmar que a satisfação no trabalho (worksatisfaction) tem duas vertentes, uma concreta e outra simbólica. A satisfação concreta está relacionada, por um lado, às exigências da tarefa e por outro às necessidades de descarga das energias. A satisfação simbólica está relacionada com o sentido do trabalho em suas relações com os desejos pessoais. Ambas expressam a relação entre o aparelho psíquico e a organização do trabalho.

Para as vivências de sofrimento no trabalho, foram avaliadas outras duas dimensões. A primeira delas foi o "Esgotamento Profissional" relacionado às situações de frustração, insegurança, inutilidade, desgaste e estresse no trabalho. Esta dimensão também foi avaliada de forma satisfatória por $33,33 \%$, assim como crítica pelo mesmo percentual. No entanto, os resultados das médias gerais conforme tabela $6(\mu=3,01 ; \sigma=1,63)$ mostram que a dimensão Esgotamento Profissional apresentou avaliações críticas quanto à vivência de sofrimento. Os itens desta dimensão que obtiveram as maiores médias foram "esgotamento emocional"; "estresse"; "sobrecarga" com médias $\mu=3,53$, $\mu=4,07$, e $\mu=3,80$, respectivamente. No entanto, o único item considerado grave pelos funcionários foi o "estresse", contribuindo para a avaliação negativa dessa dimensão.

De maneira geral, os serviços de alimentação impõe aos trabalhadores uma carga de trabalho bastante pesada, com ritmo acelerado e pressão temporal entre o preparo e a distribuição das refeições, o que pode gerar fadiga e estresse.

Para finalizar as vivências de sofrimento, foi avaliada a dimensão "falta de reconhecimento" que reflete as condições de injustiça, indignação e desvalorização devido ao não reconhecimento do trabalho. Esta dimensão também foi avaliada de forma crítica por $53,33 \%$ dos funcionários, todavia é importante ressaltar que um percentual expressivo (40\%) avaliou como satisfatório, de acordo com a Tabela 5. No entanto, os resultados das médias gerais $(\mu=2,37 ; \sigma=1,43)$ mostram que esta dimensão apresentou avaliações críticas quanto à vivência de sofrimento.

Nesta dimensão, os itens que obtiveram as maiores médias foram "falta de reconhecimento de meu esforço"; "falta de reconhecimento de meu desempenho"; "injustiça”, segundo Quadro 4, com médias $\mu=4,00, \mu=3,93$, e $\mu=2,93$, respectivamente. No entanto, o único item considerado grave pelos funcionários foi o "falta de reconhecimento de meu esforço", contribuindo para a avaliação negativa dessa dimensão.

Os resultados demonstram que há falta de reconhecimento e de valorização profissional, possivelmente pela instituição que os expõe a precárias condições de trabalho. Os resultados para esta dimensão desta pesquisa estão de acordo com Ferreira e Mendes (2003) que concluíra, que para os auditores fiscais da Previdência, o prazer e o sofrimento são vivenciados de forma moderada, pois nem sempre há o atendimento às necessidades profissionais nesse ambiente de trabalho.

Parte-se, agora, para a discussão sobre as dimensões e itens da EADRT - Escala de Avaliação de Danos Relacionados ao Trabalho, que revelam as disfunções físicas, psicológicas e sociais. Essas disfunções surgem mediante o sofrimento frequente e intenso, e do insucesso das estratégias de mediação.

Quanto aos resultados obtidos com a aplicação da Escala Danos Físicos e Psicossociais, estes apontam para uma percepção suportável para os três fatores: danos físicos, emocionais e sociais, conforme demonstrado na Tabela 7.

Tabela 7 . Percentual dos respondentes para a Escala dos Danos Relacionados ao Trabalho - EADRT

\begin{tabular}{l|c|c|c}
\hline \multicolumn{1}{c|}{ Níveis } & $\begin{array}{c}\text { Danos } \\
\text { Físicos }\end{array}$ & $\begin{array}{c}\text { Danos } \\
\text { Sociais }\end{array}$ & $\begin{array}{c}\text { Danos } \\
\text { Psicológicos }\end{array}$ \\
\hline $\begin{array}{l}\text { Presença } \\
\text { de Doenças } \\
\text { Ocupacionais }\end{array}$ & $0 \%$ & $0 \%$ & $6,67 \%$ \\
\hline Grave & $20 \%$ & $6,67 \%$ & $0 \%$ \\
\hline Crítico & $20 \%$ & $26,67 \%$ & $40 \%$ \\
\hline Suportável & $\mathbf{6 0 \%}$ & $\mathbf{6 6 , 6 7 \%}$ & $\mathbf{5 3 , 3 3 \%}$ \\
\hline
\end{tabular}

Fonte: Dados da Pesquisa, 2012. 
Analisando a dimensão Danos Físicos, que diz respeito aos distúrbios biológicos pelo trabalho, observou-se que $60 \%$ dos funcionáriosavaliaram como suportável, mostrando que existe uma percepção positiva dessa dimensão na Unidade. Conforme pode ser observado na Tabela 8 , os resultados das médias gerais $(\mu=1,92$; $\sigma=1,08)$ mostram que a dimensão danos físicos apresenta avaliações suportáveis.

Tabela 8 . Estatística descritiva referente às dimensões da EADRT

\begin{tabular}{l|c|c|c}
\hline \multicolumn{1}{c|}{ Dimensões } & Média & $\begin{array}{c}\text { Desvio } \\
\text { Padrão }\end{array}$ & $\begin{array}{c}\text { Alpha } \\
\text { Cronbach }\end{array}$ \\
\hline Danos Físicos & 1,92 & 1,08 & 0,85 \\
\hline Danos Sociais & 1,39 & 1,14 & 0,86 \\
\hline $\begin{array}{l}\text { Danos } \\
\text { Psicológicos }\end{array}$ & 1,55 & 1,31 & 0,87 \\
\hline
\end{tabular}

Fonte: Dados da Pesquisa, 2012.

Nesta dimensão, os itens que obtiveram as maiores médias foram "dores nos braços"; "alterações no sono"; “dores nas pernas", segundo Quadro 5, com médias $\mu=2,53, \mu=3,13$, e $\mu=2,73$, respectivamente.

Quadro 5 . Resumo sobre EADRT, suas dimensões e itens avaliados com maior média

\begin{tabular}{|c|c|c|}
\hline \multirow{3}{*}{$\begin{array}{c}\text { Danos } \\
\text { Relacionados } \\
\text { ao Trabalho }\end{array}$} & Danos Físicos & $\begin{array}{ll}\text { - } & \text { Dores nos braços } \\
\text { - } & \text { Alterações no sono } \\
\text { - } & \text { Dores nas pernas }\end{array}$ \\
\hline & Danos Sociais & $\begin{array}{l}\text { - Insensibilidade em } \\
\text { relação aos colegas } \\
\text { - Vontade de ficar } \\
\text { sozinho } \\
\text { - Conflitos nas } \\
\text { relações familiares } \\
\text { - Impaciência com } \\
\text { as pessoas em geral }\end{array}$ \\
\hline & $\begin{array}{c}\text { Danos } \\
\text { Psicológicos }\end{array}$ & $\begin{array}{l}\text { - } \text { Mau - humor } \\
\text { - Vontade de desistir } \\
\text { de tudo } \\
\text { - } \quad \text { Tristeza }\end{array}$ \\
\hline
\end{tabular}

Fonte: Dados da Pesquisa, 2012.

Embora os resultados do construto Danos Físicos se apresentem como suportáveis, Moreira e Mendes
(2005), afirmam que o ambiente de trabalho, considerando-se condições físicas, mecânicas e psíquicas inadequadas, é um importante fator de risco para o desenvolvimento de DORT - Distúrbio Osteomuscular Relativo ao Trabalho.

No que diz respeito à dimensão Danos Sociais, definida como dificuldade nas relações familiares e sociais, observou-se que $66,67 \%$ dos funcionários avaliaram como suportável, de acordo com a Tabela 7, mostrando que existe uma percepção positiva dessa dimensão na Unidade. Os resultados das médias gerais $(\mu=1,39$; $\sigma=1,14)$ mostram que a dimensão danos sociais apresentaram avaliações suportáveis, conforme Tabela 8. Nesta dimensão, os itens que obtiveram as maiores médias foram "insensibilidade em relação aos colegas"; "vontade de ficar sozinho"; "conflitos nas relações familiares" e "impaciência com as pessoas em geral" com médias $\mu=1,67, \mu=$ $2,40, \mu=1,67$ e $\mu=2,07$, respectivamente.

Finalizando a escala dos danos relacionados ao trabalho, foi avaliada a dimensão Danos Psicológicos, representando os sentimentos negativos em relação a si mesmo e a vida em geral, cujos resultados foram semelhantes às outras duas dimensões, ou seja, a maioria dos funcionários avaliou como suportável (53,33\%), de acordo com a Tabela 7 ,que corresponde à avaliação das médias gerais $(\mu=1,55 ; \sigma=1,31)$, segundo dados da Tabela 8 . Para esta mesma dimensão, de acordo com o Quadro 5 , os itens que obtiveram as maiores médias foram "mau humor"; "vontade de desistir de tudo"; e "tristeza" com médias $\mu=2,00, \mu=2,40, \mu=2,33$ e $\mu=1,73$, respectivamente.

Por fim, observou-se que a população estudada é predominantemente jovem (20 a 30 anos) e do sexo masculino, acredita-se que esse perfil seja pelo tipo de trabalho exercido na unidade de alimentação, uma vez que requer uma sobrecarga física além da polivalência de suas funções. Dessa forma, verificouse que as condições e organização do trabalho foram avaliadas de forma crítica em decorrência da gestão do trabalho, divisão e ritmos de trabalho além da qualidade do ambiente e material disponibilizado.

Dentro desse contexto do trabalho, percebe-se que essa organização, assim como as condições de trabalho levaram a um dispêndio emocional, intelectual e esforço corporal, fazendo com que o custo humano do trabalho tenha sido avaliado de forma crítica a grave. 
Diante desse cenário e corroborando com estes resultados, observam-se, de forma predominante, vivências de sofrimento. Porém, quando foram avaliados os danos relacionados ao trabalho, viu-se que esta escala encontra-se suportável, resultado este que pode ter relação com o tempo de serviço (até 2 anos) e/ou faixa etária dos respondentes. No Quadro 6, a seguir, é apresentada uma síntese dos resultados aqui encontrados.

Quadro 6. Síntese dos resultados encontrados

\begin{tabular}{|l|l|}
\hline \multicolumn{2}{|c|}{ Perfil Sociodemográfico } \\
\hline Faixa Etária & 20 a 30 anos \\
\hline Gênero & Masculino \\
\hline Escolaridade & Ensino Médio \\
\hline Estado Civil & Solteiro \\
\hline $\begin{array}{l}\text { Tempo de serviço na } \\
\text { unidade }\end{array}$ & Até 02 anos \\
\hline $\begin{array}{l}\text { Tempo de serviço no } \\
\text { cargo }\end{array}$ & Até 02 anos \\
\hline Exame Médico & Sim \\
\hline Afastamento & Nenhum \\
\hline \multicolumn{2}{|c|}{ Condições e organização do trabalho } \\
\hline $\begin{array}{l}\text { Organização do } \\
\text { trabalho }\end{array}$ & Grave e Crítico \\
\hline $\begin{array}{l}\text { Relações } \\
\text { socioprofissionais }\end{array}$ & Crítico \\
\hline $\begin{array}{l}\text { Condições de } \\
\text { trabalho }\end{array}$ & Crítico \\
\hline Custo Humano do trabalho \\
\hline Custo Afetivo & Crítico \\
\hline Custo Cognitivo & Crítico/Satisfatório \\
\hline Custo Físico & Grave \\
\hline \multicolumn{2}{|c|}{ Indicadores de Prazer e Sofrimento no trabalho } \\
\hline $\begin{array}{l}\text { Liberdade de } \\
\text { Expressão }\end{array}$ & Crítico \\
\hline $\begin{array}{l}\text { Realização } \\
\text { Profissional }\end{array}$ & Imparcial \\
\hline $\begin{array}{l}\text { Esgotamento } \\
\text { Profissional }\end{array}$ & Imparcial \\
\hline $\begin{array}{l}\text { Falta de } \\
\text { Reconhecimento }\end{array}$ & Crítico \\
\hline \multicolumn{2}{|c|}{ Supolacionados ao trabalho } \\
\hline Danos Físicos & Suportável \\
\hline Danos Sociais & Suportável \\
\hline Danos Psicológicos \\
\hline
\end{tabular}

Fonte: Dados da Pesquisa, 2012.
Desse modo, é possível inferir que o contexto de trabalho investigado provoca danos físicos, psíquicos e sociais a esses trabalhadores, favorecendo os riscos de adoecimento, cujos sinais já se encontram presentes em alguns indivíduos pesquisados.

\section{Considerações finais}

Esta pesquisa teve por objetivo principal avaliar as condições e organização do trabalho que se relacionam com a dinâmica do prazer-sofrimento dos colaboradores de uma Unidade de Alimentação e Nutrição Hoteleira. A partir do presente estudo, evidenciamos a coexistência das vivências de prazer e sofrimento dos trabalhadores, permitindo a avaliação e discussão sobre a influência da organização e dinâmica do trabalho, e os riscos à saúde.

O perfil sociodemográfico dos respondentes foi predominantemente masculino, de 20 a 30 anos, solteiros e com ensino médio como escolaridade, não ultrapassando dois anos de tempo de serviço.

Quando da avaliação das condições e organização do trabalho através da Escala do contexto do trabalho, observou-se que as dimensões organização do trabalho, relações socioprofissionais e condições de trabalho encontram-se de forma crítica a grave, de acordo com os respondentes. Tal fato revela uma diferenciação de outras propostas de estudos já existentes.

No que diz respeito ao custo humano do trabalho, avaliado através das dimensões custo afetivo, custo cognitivo e custo físico foram apontados de forma crítica pelos funcionários pesquisados.

Já os indicadores de prazer e sofrimento avaliados pelas dimensões liberdade de expressão, realização profissional, esgotamento profissional e falta de reconhecimento foram encontradas mais nas vivências de sofrimento do que prazer.

Observou-se de forma predominante na análise vivências de sofrimento. Porém, quando avaliados os danos relacionados ao trabalho por meio das dimensões danos físicos, sociais e psicológicos, viu-se que os índices encontram-se suportáveis, verificação esta que pode ter relação com o tempo de serviço (até 2 anos) e/ou faixa etária dos respondentes.

Para os danos físicos, dimensão que diz respeito aos distúrbios biológicos pelo trabalho, observou-se que $60 \%$ dos funcionários avaliaram como suportável, 
mostrando que existe uma percepção positiva dessa dimensão na Unidade.

No que se trata de danos psicológicos, representando os sentimentos negativos em relação a si mesmo e a vida em geral, a maioria dos funcionários avaliou como suportável $(53,33 \%)$, correspondendo a avaliação correspondente das médias gerais $(\mu=1,55 ; \sigma=1,31)$.

No que diz respeito aos danos sociais, definido como dificuldades nas relações familiares e sociais, foi observado que $66,67 \%$ dos funcionários avaliaram como suportável, mostrando que existe uma percepção positiva dessa dimensão na Unidade.

Logo pode-se inferir que o contexto de trabalho investigado provoca danos físicos, psíquicos e sociais nesses trabalhadores, favorecendo os riscos de adoecimento, cujos sinais já se encontram presentes em alguns indivíduos pesquisados.

Contudo, propõe-se para uma avaliação mais completa a associação de métodos qualitativos, a exemplo de discussões em grupo, sendo a entrevista coletiva a mais indicada para investigar as vivências de prazersofrimento.

Os limitantes desta pesquisa foram a existência de apenas dois estudos com funcionários de UAN; a extensão do instrumento composto por 4 escalas, com um total de 125 itens, tornando-se cansativo respondêlo, o que pode ter gerado respostas inconsistentes.

Esta pesquisa evidenciou um modelo de gestão do processo de trabalho taylorizado. A recorrência de alguns construtos durante a apresentação dos resultados evidencia o peso da organização do trabalho na saúde destes trabalhadores. Foram pontuadas aqui algumas recomendações, como: novos estudos sobre organização do trabalho; possíveis modificações nas características de administração e organização para uma maior sensibilização quanto à saúde do trabalhador.

Por fim, as empresas do segmento de alimentação precisam avaliar a organização do trabalho, concentrar esforços na identificação, eliminação, neutralização ou controle dos riscos ocupacionais no ambiente de trabalho e na promoção da qualidade de vida no trabalho, através da valorização das condições de trabalho, da definição de procedimentos da tarefa, do cuidado com o ambiente físico e dos bons padrões de relacionamento.

\section{Referências}

ABREU, E. S. de, SPINELLI, M. G. N., PINTO, A. M. de S. Gestão de unidades de alimentação e nutrição: um modo de fazer. São Paulo: Editora Metha, 2009.

ALVES, F. S., A Organização da Produção de Unidades de Alimentação. Dissertação (Mestrado em Administração). Universidade Federal de Santa Catarina. Florianópolis, 2005

BARROS, P.C.R.; MENDES, A.M.B. Sofrimento psíquico no trabalho e estratégias defensivas dos operários da construção civil. Psico-UFS. Brasilia, v.8, n.1, jan./jun. 2003. P. 63-70.

BRIEF, A. P., NORD, W.R. Meaning of occupational work. Toronto: Lexington Books, 1990.

COLARES, L. G. T., Evolução e perspectivas do programa de alimentação do trabalhador no contexto político brasileiro. Rev. Sociedade brasileira de nutrição, São Paulo,SP. v.29, p.141-148, 2005.

COLARES, L. G.T. ; FREITAS, C. M. Processo de trabalho e saúde de trabalhadores de uma unidade de alimentação e nutrição: entre a prescrição e o real do trabalho. Cadernos Saúde Pública. Rio de Janeiro, v.23, n. 12, dez. 2007. p. 3011-3020.

DEJOURS, C. A banalização da injustiça social.

7. Ed. Rio de Janeiro: Ed. Fundação Getúlio Vargas, 2006, 158p.

DEJOURS, C. A loucura do trabalho - estudo de psicopatologia do trabalho. 3 ed. São Paulo: CortezOboré. 1988.

DEJOURS, C. A loucura do trabalho - estudo de psicopatologia do trabalho. Tradução de Ana Isabel Paraguay e Lúcia Leal Ferreira. São Paulo: Cortez Oboré, 1992. Tradução de: Travail, UsureMentale.

DEJOURS, C. Subjetividade, trabalho e ação.

Revista Produção. v. 14, n. 3. set./Dez. 2004. p.27 -34 .

DEJOURS,C; ABDOUCHELI, E.; JAYET, C.. Psicodinâmica do trabalho: contribuições da escola dejouriana à análise da relação prazer, sofrimento e trabalho. São Paulo: Ed. Atlas, 1994.145p.

DEJOURS, C.; DESSORS, D.; DESRIAUX, F. 
Por um trabalho, fator de equilíbrio. Revista de Administração de Empresas. São Paulo, v.33, n.3, maio-jun, 1993.

FERREIRA, M. C.; MENDES, A. M. Só de pensar em vir trabalhar, já fico de mau- humor: atividade de atendimento ao público e prazer-sofrimento no trabalho. RevistaEstudos de Psicologia. v.6, n. 1, 2001. p. 93-104.

FERREIRA, M. C.; MENDES, A. M. Trabalho e riscos de adoecimento: o caso dos auditores fiscais da Previdência Social brasileira. Brasília, DF: Edições LPA e FENAFISP, 2003.

FONSECA, M. T. Tecnologias gerenciais de restaurantes. São Paulo: Editora Senac São Paulo, 2006.

HOPNER, A. Políticas de Recurso Humanos e Qualidade de vida no trabalho em redes hoteleiras. 2008. 332f. Dissertação (Mestrado em Administração). Universidade Federal do Rio Grande do Sul. Porto Alegre, 2008.

KANAANE, R. Comportamento humano nas organizações: o homem rumo ao século XXI. São Paulo: Atlas, 2007.

KARASEK, R; THEORELL T. Healthy work: stress, productivity and the reconstruction of working life. New York: Basic Books, 1990.

KETCHUM, L. D., TRIST, E. All teams are not created equal: how employee empowerment really works.NewburyPark :Sage, 1992.

LANZILLOTTI, H.S. Terceirização em serviços de alimentação: ensaio exploratório. Revista de Nutrição PUC CAMP. Campinas, v 9, n.1, jan./jun. 1996. P. 9-35.

LIMA, F. B. Stress, qualidade de vida, prazer e sofrimento no trabalho de Call Center.2004. 133f. Dissertação (Mestrado em Psicologia). PUCCampinas, 2004.

LOBO, A. Manual de Estrutura e Organização do Restaurante Comercial. 2ed. São Paulo: Editora Atheneu, 2009.

MATOS, C. H. Condições de Trabalho e Estado Nutricional de Operadores do Setor de Alimentação Coletiva: Um estudo de Caso. Dissertação (Mestrado em Engenharia de Produção). Universidade Federal de Santa Catarina. Florianópolis, 2000 .
MEDEIROS, B.V. Síndrome de burnout e a centralidade do trabalho na docência: estudo de caso numa universidade pública. Dissertação (Mestrado em Administração). Universidade Potiguar. Natal, 2011.

MEIRELES, I. A. C. O impacto das percepções de justiça organizacional sobre as vivencias de prazer e sofrimento no trabalho. Dissertação (Mestrado em Psicologia). Universidade Católica de Goiás. Goiânia, 2006.

MENDES, A. M. (org). Psicodinâmica do trabalho: teoria, método e pesquisas. São Paulo: Casa do psicólogo, 2007.

MENDES, A. M. M.; TAMAYO, A. Valores organizacionais e prazer-sofrimento o trabalho. PsicoUSF. v.6, n.1, jan./jun. 2001. P.39-46.

MOREIRA A.M.R.; MENDES, R. Fatores de risco dos distúrbios osteomusculares relacionados ao trabalho. UERJ, Rio de Janeiro, 2005.

PEREIRA, J. S. Vivências de prazer-sofrimento em gerentes de empresa estratégica: impacto dos valores organizacionais. 2003. Dissertação de mestrado em Psicologia. Universidade de Brasília, Brasília, 2003.

PRADO, F. de A. Prazer: a energia dos vencedores. São Paulo : Editora Mercuryo. 1998. 183 p.

PROENÇA, R. P. C. Inovações tecnológicas na produção de alimentação coletiva. 3 ed. Florianópolis: Editora Insular, 2009.

RESENDE, S. Vivências de prazer e sofrimento no trabalho bancário: o impacto dos valores individuais e das variáveis demográficas. 2003, 129f. Dissertação (Mestrado em Psicologia) Departamento de Psicologia social e do Trabalho, Universidade de Brasília, Brasília, 2003.

RIBEIRO, C. S. G. Análise de Perdas em Unidades de Alimentação e Nutrição (UANs) Industriais: Estudo de Caso em Restaurantes Industriais. Dissertação (Mestrado em Engenharia da Produção) Universidade Federal de Santa Catarina, Florianópolis, 2002 .

SANTOS, C. M. F. Dinâmica do Prazer-Sofrimento na Organização do Trabalho da Enfermeira. 2008. 134 f. Dissertação (Mestrado em Enfermagem) - Escola de Enfermagem, Universidade Federal da Bahia, Salvador, 2008. 
SHEPHERDSON, K. V. The meaning of work and employment : psychological research and psychologists' values. Australian Psychologist, v. 19, n. 3, p. 311-320,1984.

SCHUTZ, W. C. O prazer expansão da consciência humana. Rio de Janeiro : Imago Editora Ltda., 1974. 189 p.

TEIXEIRA, S. M. F., OLIVEIRA, Z. M. C., REGO, J. C. Administração Aplicada às Unidades de Alimentação e Nutrição. São Paulo: Livraria Atheneu, 2004.

TOLEDO, D. A. C.; GUERRA, A. C. Um estudo sobre o prazer no trabalho: Pensando dimensões de análise. In: XXXIII Encontro da ANPAD. São Paulo/SP, set. 2009.

TORRES, C.T.; ABRAHÃO, J.I. A atividade de teleatendimento: uma análise das fontes de prazer e sofrimento no trabalho. Revista brasileira de saúde ocupacional. São Paulo, v.31, n.114, 2006. P. 113124.

TRIVIÑOS, A. N. S. Introdução à pesquisa em ciências sociais: a pesquisa qualitativa em educação. São Paulo: Atlas, 1987. 175p.

VERGARA, S. C. Métodos de pesquisa em administração. 2. ed., São Paulo: Atlas, 2006. 287p.

YIN, R. K. Estudo de Caso: planejamento e métodos. Porto Alegre: Bookman, 2001. 